\title{
Seamless Handoff using Electre III and Promethee Methods
}

\author{
G.A. Preethi \\ Dept of Computer Science \\ Periyar University, Salem, TamilNadu
}

\author{
C. Chandrasekar, $\mathrm{PhD}$ \\ Dept of Computer Science \\ Periyar University, Salem, TamilNadu
}

\begin{abstract}
Communication in mobility without interruptions has become a challenge these days. Mobile devices progressing in remote areas will expect low signal levels and sometimes no signal. If a mobile node's service provider coverage doesn't support for long ranges, then it shifts to a new base station. So then a handoff occurs. If the same networks base station is available then there is no bar to continue with the same network. If it has to opt for other networks, different types of criterions have to be considered. In this paper, two Multiple Attribute Decision Making(MADM) methods has been employed and recognized as ELECTRE III and PROMETHEE methods which contrive the networks based on criterion performances for handoff decision. The main objective is to reduce the unwanted handoff and to reduce the handoff failures. Evaluation of alternatives such as GSM, EDGE and CDMA has been processed. ELECTRE III method has been exploited as the construction of Concordance, Discordance and Credibility index. Criteria such as Datarate, Packet Loss, Speed, Bandwidth, Signal and Jitter has been discussed. PROMETHEE method utilizes preference function and plots GAIA plane to easy perceptive of network behaviors. The comparison of ELECTRE III and PROMETHEE methods resulted in superior interpretation of MADM methods.
\end{abstract}

\section{Keywords}

Concordance, Credibility, Discordance, ELECTRE III,GAIA, Preference function, PROMETHEE, Vertical Handoff.

\section{INTRODUCTION}

Mobile technology has made a revolution in which it resulted in ubiquitous technology. The Mobile Communication techniques have reached a level that diminished the usage of documents. In this fast moving scenario, data transmission should be end to end perfect. Mobile nodes support by the base station is within a cell range. Possible handoffs will be numerically large in fast moving mobile nodes. Nodes will experience ping-pong effects if it changes its base station periodically. To overcome these issues, we need to select the proper network for handoff. For handoff decision making, we use Multiple Attribute Decision Making ( MADM ) as well as Multiple Criteria Decision Making ( MCDM ) methods. If a Mobile node changes its base station or access point within its range, signal strength is the main criteria to be resolved. Even if it proceeds beyond the level and the same network support is available, it is termed as Horizontal Handoff. If there is no network access from the same base station, then the mobile device has to send request to the available networks in proximity. Here it is known as Heterogeneous Handoff. It requires a variety of criterion to be satisfied for handoff roaming.
In this article, the Multiple Attribute Decision Making (MADM) methods such as ELECTRE III and PROMETHEE has been implemented, the "best" network is selected. This article is organized as follows: Section II introduces the related work in this subject matter. Section III , describes our MADM methods such as ELECTRE III and PROMETHEE methods. The Simulation and the Output and analysis are presented in sections IV and V. Finally, Section VI concludes this article.

\section{RELATED WORK}

Certain handoff decision algorithms have been proposed in the literature. In [1], authors evaluated the vertical handoff decision via adaptive vertical handoff decision making algorithm in which fuzzy membership functions are optimized by means of genetic algorithm. Author proposed a Multi Criteria Decision Making system in [2], which is termed as ELECTRE Method, in which it is widely used in all other fields. A different approach is conceived by the authors in [3] by combining the idea of Analytical Hierarchy Process (AHP) with PROMETHEE method for Multi Criteria Decision Making. Authors implemented AHP and Ordered Weighted Approach ( OWA ) methods for handoff decision making in [6].

In [7] authors proposed a decision making algorithm for seamless vertical handover between WiFi hotspots and an overlay WiMAX network. The Parameters they have used are Received Signal Strength and End to End TCP handover Latency. Authors proposed a novel preference ranking organization method by similarity to ideal solution (PROMSIS) vertical handoff algorithm for heterogeneous wireless networks in [8], and its essential idea includes the preference structure of the PROMETHEE and the concept of Euclid distance of the TOPSIS. Authors mainly analyzed the traffic patterns such as streaming, interactive, conversational etc. In [9] authors designed a middleware framework to support user mobility in the ubiquitous computing environment. Its major mobility functions include user-level handoff management and service instantiation across heterogeneous computing platforms.

In all these previous works, the authors implementation is being deficient in some perspective. Spotlight of the vertical handoff decision should be in all possible aspects. Significant parameters such as Signal Strength, Velocity, Packet Loss, Data Rate and Throughput of the Networks should be considered as vital things. In the next section, we propose two different types of vertical handoff decision schemes named as ELECTRE III method and PROMETHEE Method. 


\section{MULTIPLE ATTRIBUTE (/ CRITERIA) DECISION MAKING (MADM)}

The MADM method is based ELECTRE III. however we apply it in a distributed manner. Thus, we place the computing processing in the visited networks rather than on the mobile terminal. MADM allows the terminal to choose the "best" network towards which it will be connected. The MADM method consists of the following steps:

- The Mobile Terminal Broadcasts a handoff Request message. The handoff decision metric calculation is performed on the VNs, each VN applies the MADM method

- Finally, the mobile terminal chooses the highest quality value network as the potential $\mathrm{VN}$ for Handoff.

\subsection{The ELECTRE III method}

ELECTRE was conceived by Bernard Roy [2] in response to paucities of existing decision making solution methods. ELECTRE is more than just a solution method. It is a philosophy of decision aid - the philosophy is discussed at length by B.Roy [2]. However, for this paper we shall concentrate on the ELECTRE III method.

The ELECTRE III method is an outranking method. The construction of outranking relation requires the definition of a credibility index, which characterizes the credibility of the assertion " outranks ", $a S b$. It is defined by using both the concordance index, and a discordance index for each criterion $c_{j}$.

In this method, each criterion has three values associated to its description:

- $q_{j}$ Indifference threshold for a criterion . $c_{j}$

- $p_{j}$ Preference threshold for a criterion $c_{j}$.

- $v_{j}$ Veto preference for a criterion $c_{j}$.

Another important consideration of outranking methods is that the values in the performance table, $c_{j}\left(\mathrm{a}_{\mathrm{x}}\right)$, do not necessarily represent utility values. In fact, one of the main characteristics of this approach is that we can work with different performance scales in different criteria, provided that they define a total order among the set of alternatives. In that sense, each criterion can be maximized or minimized, depending on its interpretation.

In the following sections[4], the procedures for calculating the concordance, discordance and credibility values are explained. The reader should take into account that when we are defining our criteria and alternatives, it is necessary to choose if whether significance given to low values or to the high values. If we choose to give preference to the small values, we will have to calculate the difference between alternatives $a_{x 1}$ and $a_{x 2}$ in the following way:

$$
\text { Diff }=-\left(c_{j}\left(a_{x 1}\right)-c_{j}\left(a_{x 2}\right)\right)
$$

Otherwise, if we want to give preference to the high values, we will apply the following formula:

$$
\text { Diff }=\left(c_{j}\left(a_{x 1}\right)-c_{j}\left(a_{x 2}\right)\right)
$$

\subsection{Generation of the concordance matrix in ELECTRE III}

To calculate the concordance matrix, we have to evaluate each pair of alternatives with their respective criteria. The preference $\left(p_{j}\right)$ and indifference $\left(q_{j}\right)$ thresholds are used to construct a concordance index Concordance $_{j}\left(a_{x 1}, a_{x 2}\right)$ for each criterion, defined by:

Concordance $_{j}\left(a_{x 1}, a_{x 2}\right)=\left\{\frac{\text { Diff }+p_{j}}{p_{j}-q_{j}}\right.$ else

, ( 0 if Diff $\leq-p_{j}$ ) or ( 1 if Diff $\geq-q_{j}$ )

From the partial concordance, we calculate the overall concordance index:

$C_{j}\left(a_{x 1}, a_{x 2}\right)=\frac{\sum w_{j} * C_{j}\left(a_{x 1}, a_{x 2}\right)}{\sum w_{j}}$

\subsection{Generation of the discordance matrix in ELECTRE III}

Discordance is defined similarly by the introduction of a veto threshold for each criterion say $v_{j}$ for criterion $c_{j}$, such as outranking of $b$ by $a$ is vetoed if the performance $b$ exceeds that of $a$ by an amount greater than the veto threshold. A corresponding discordance index for each criterion is defined by:

$$
\begin{aligned}
& \text { Discordance }_{j}\left(a_{x 1}, a_{x 2}\right)=\left\{\frac{\text { Diff }-p_{j}}{v_{j}-p_{j}}\right. \text { else } \\
& ,\left(0 \text { if }\left(\text { Diff } \leq p_{j} \| v_{j}\right) \text { or }\left(1 \text { if } \text { Diff } \geq v_{j}\right)\right.
\end{aligned}
$$

\subsection{Generation of the credibility index in ELECTRE III}

The credibility index is defined as follows:

$$
\begin{aligned}
& S\left(a_{x 1}, a_{x 2}\right)=\left\{C_{j}\left(a_{x 1}, a_{x 2}\right),\right. \\
& \text { if } D_{j}\left(a_{x 1}, a_{x 2}\right) \leq C_{j}\left(a_{x 1}, a_{x 2}\right) \forall_{j} \\
& S\left(a_{x 1}, a_{x 2}\right)=C_{j}\left(a_{x 1}, a_{x 2}\right) \prod_{j \in J\left(a_{x 1}, a_{x 2}\right)} \frac{\left(1-D_{j}\left(a_{x 1}, a_{x 2}\right)\right)}{\left(1-C_{j}\left(a_{x 1}, a_{x 2}\right)\right)}
\end{aligned}
$$

Where $J\left(\mathrm{a}_{\mathrm{x} 1}, \mathrm{a}_{\mathrm{x} 2}\right)$ is the set of criteria for which:

$$
\operatorname{Discordance}\left(a_{x 1}, a_{x 2}\right)>\text { Concordance }\left(a_{x 1}, a_{x 2}\right)
$$

\subsection{Handoff Decision: a fuzzy ELECTRE III problem}

Handover Decision deals with making selection from various service providers and technologies with respect to different criteria. Hence it is a typical MADM problem[3]. For instance, Suppose a user is currently connected to a Network $\left(\mathrm{N}_{0}\right)$ and has to make decision among six available Networks 
such as a01, a02, a03, a04, a05 and a06. Handoff Criteria considered here are Data Rate, Packet Loss, Speed, Bandwidth, Signal Strength and Jitter. The Network Selection Problem can be concisely expressed in the decision matrix Table 1, where the measures of each criterion are presented.

Weights such as $W_{j}=\left[\begin{array}{lllll}0.220 & 0.087 & 0.150 & 0.149 & 0.300\end{array}\right.$ 0.094 ] are provided. Here we have given the voice application weight. Classical MADM methods cannot efficiently handle such decision problem with imprecise data. Accordingly, over a large number of MADM methods have been developed to handle the inadequate data in MADM in the last few decades.

Table 1: Alternatives Vs Criterion Values(Linguistic Terms)

\begin{tabular}{|c|l|c|c|c|c|c|}
\hline & $\begin{array}{l}\text { Dat } \\
\text { Rat } \\
\mathrm{e}\end{array}$ & $\begin{array}{l}\text { Packe } \\
\text { t Loss }\end{array}$ & $\begin{array}{c}\text { Speed } \\
\text { (Downstrea } \\
\mathrm{m})\end{array}$ & $\begin{array}{c}\text { Band } \\
\text { widt } \\
\mathrm{h}\end{array}$ & $\begin{array}{c}\text { Signal } \\
\text { Strengt } \\
\mathrm{h}\end{array}$ & $\begin{array}{c}\text { Jitte } \\
\mathrm{r}\end{array}$ \\
\hline GSM & 115 & 19 & 40 & 20 & 19 & 1.5 \\
\hline EDGE & 474 & 17 & 28 & 25 & 24 & 1.2 \\
\hline CDMA & 144 & 21 & 15.67 & 12.5 & 15 & 1.5 \\
\hline GSM2 & 200 & 18 & 42 & 18 & 20 & 1.2 \\
\hline EDGE2 & 300 & 15 & 20 & 22 & 20 & 1.0 \\
\hline $\begin{array}{c}\text { CDMA } \\
2\end{array}$ & 200 & 20 & 14 & 14 & 18 & 1.2 \\
\hline
\end{tabular}

Threshold values are given as,

Table 2: Threshold Values

\begin{tabular}{|c|c|c|c|c|c|c|}
\hline & $\begin{array}{c}\text { Data } \\
\text { Rate }\end{array}$ & $\begin{array}{c}\text { Packet } \\
\text { Loss }\end{array}$ & Speed & $\begin{array}{c}\text { Band } \\
\text { width }\end{array}$ & $\begin{array}{c}\text { Signal } \\
\text { Strength }\end{array}$ & Jitter \\
\hline Preference & 250 & 12 & 25 & 20 & 20 & 1.2 \\
\hline Indifference & 200 & 10 & 20 & 17 & 18 & 1.0 \\
\hline Veto & 350 & 20 & 35 & 24 & 24 & 1.5 \\
\hline
\end{tabular}

Corresponding weights are multiplied with the respective criterions. All other networks are compared pair wise to find the Concordance Matrix. The Concordance Matrix is given by Table 3. The ELECTRE III method is implemented in a software known as Diviz[4], which is a MCDM support software used in various fields. The Alternatives and Criterions are defined in an input file known as XMCDA file. XMCDA is written with the help of XML language. The Discordance values are almost zero.

Table 3: Concordance Matrix

\begin{tabular}{|c|c|c|c|c|c|c|}
\hline & $\begin{array}{c}\text { GSM } \\
(\mathrm{a} 01)\end{array}$ & $\begin{array}{c}\text { EDGE } \\
(\mathrm{a} 02)\end{array}$ & $\begin{array}{c}\text { CDM } \\
\text { A } \\
(\mathrm{a} 03)\end{array}$ & $\begin{array}{c}\text { GSM2 } \\
(\mathrm{a} 04)\end{array}$ & $\begin{array}{c}\text { EDGE } \\
\text { 2(a05) }\end{array}$ & $\begin{array}{c}\text { CDMA } \\
\text { 2(a6) }\end{array}$ \\
\hline $\begin{array}{c}\text { GSM } \\
(\mathrm{a} 01)\end{array}$ & 1 & 0.78 & 1 & 1 & 1 & 1 \\
\hline $\begin{array}{c}\text { EDG } \\
\text { E(a02 } \\
\text { ) }\end{array}$ & 1 & 1 & 1 & 1 & 1 & 1 \\
\hline $\begin{array}{c}\text { CDM } \\
\text { A } \\
(\mathrm{a} 03)\end{array}$ & 0.87 & 0.78 & 1 & 0.85 & 1 & 1 \\
\hline $\begin{array}{c}\text { GSM } \\
\text { 2(a04 } \\
\text { ) }\end{array}$ & 1 & 0.78 & 1 & 1 & 1 & 1 \\
\hline $\begin{array}{c}\text { EDG } \\
\text { E2(a0 } \\
5)\end{array}$ & 1 & 1 & 1 & 0.94 & 1 & 1 \\
\hline $\begin{array}{c}\text { CDM } \\
\text { A2(a } \\
\text { 06) }\end{array}$ & 0.85 & 0.78 & 1 & 0.85 & 1 & 1 \\
\hline
\end{tabular}

Outranking relation is calculated and given as

Table 4: Outranking Relation

\begin{tabular}{|c|c|c|c|c|c|c|}
\hline & $\begin{array}{c}\text { GSM } \\
(\mathrm{a} 01)\end{array}$ & $\begin{array}{c}\text { EDGE } \\
(\mathrm{a} 02)\end{array}$ & $\begin{array}{c}\text { CDM } \\
\mathrm{A} \\
(\mathrm{a} 03)\end{array}$ & $\begin{array}{c}\text { GSM2 } \\
(\mathrm{a} 04)\end{array}$ & $\begin{array}{c}\text { EDGE } \\
2 \\
(\mathrm{a} 05)\end{array}$ & $\begin{array}{c}\text { CDM } \\
\mathrm{A} 2 \\
(\mathrm{a} 06)\end{array}$ \\
\hline $\begin{array}{c}\text { GSM } \\
(\mathrm{a} 01)\end{array}$ & 1 & 0 & 1 & 1 & 1 & 1 \\
\hline $\begin{array}{c}\text { EDGE } \\
(\mathrm{a} 02)\end{array}$ & 1 & 1 & 1 & 1 & 1 & 1 \\
\hline $\begin{array}{c}\text { CDM } \\
\text { A(a03) }\end{array}$ & 0.87 & 0.71 & 1 & 0.85 & 1 & 1 \\
\hline $\begin{array}{c}\text { GSM2 } \\
(\mathrm{a} 04)\end{array}$ & 1 & 0.78 & 1 & 1 & 1 & 1 \\
\hline $\begin{array}{c}\text { EDGE } \\
\text { 2(a05) }\end{array}$ & 1 & 1 & 1 & 0.94 & 1 & 1 \\
\hline $\begin{array}{c}\text { CDM } \\
\text { A2(a06 } \\
)\end{array}$ & 0.85 & 0.78 & 1 & 0.85 & 1 & 1 \\
\hline
\end{tabular}

From the Tables 6 and 7, both Concordance Matrix values and Outranking relation values are similar. We have obtained the Preorder values of alternatives and given in Fig: 1. In which it is visualized by using the ranks acquired by the alternatives from Fig: 2.

\section{Alternatives values preorder plot}

$\{a 03, a 05, a 06, a 01, a 04, a 02\}$

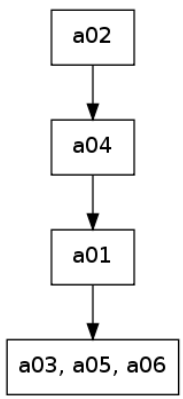

Fig 1: Preorder plot of Alternatives

\section{alternativesRanks}

\begin{tabular}{||l||l||}
\hline a03 & 1 \\
\hline \hline$a 05$ & 1 \\
\hline \hline$a 06$ & 1 \\
\hline \hline$a 01$ & 4 \\
\hline \hline$a 04$ & 5 \\
\hline \hline$a 02$ & 6 \\
\hline
\end{tabular}

Fig 2: Alternatives Ranks

The outranking relationships are displayed in graphical mode for easy understanding. It is visualized in Fig: 3. The Alternative a02 outperforms all other alternatives. Next to that a04 performs well compared to other networks, which is obtained by Fig: 5 . 
Alternatives comparisons plot

$\{\mathrm{a} 01, \mathrm{a} 02, \mathrm{a} 03, \mathrm{a} 04, \mathrm{a} 05, \mathrm{a} 06\}$

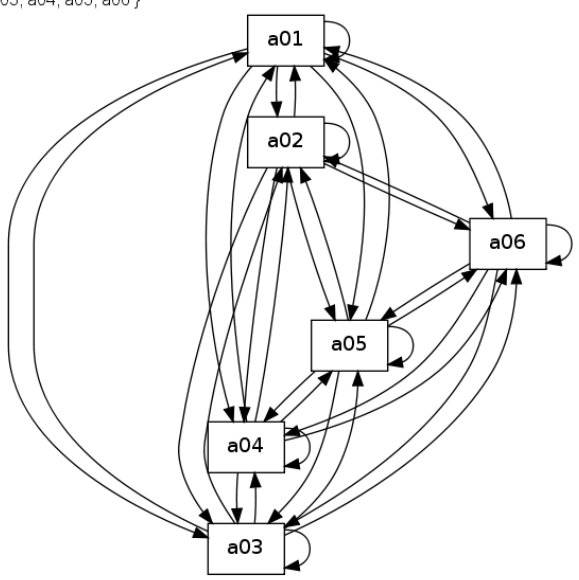

Fig3: Outranking Relationships

To find the ranking among the alternatives, two indicators are calculated, the Weakness(W) corresponds to the number of networks that outrank other network, whereas the Strength(S) is the number of networks that are outranked by the other networks. The Difference S-W is the final qualification.

\section{strength}

\begin{tabular}{||c||c||}
\hline $\mathrm{a} 01$ & 5 \\
\hline \hline $\mathrm{a} 02$ & 6 \\
\hline \hline $\mathrm{a} 03$ & 6 \\
\hline \hline $\mathrm{a} 04$ & 6 \\
\hline \hline $\mathrm{a} 05$ & 6 \\
\hline \hline $\mathrm{a} 06$ & 6 \\
\hline
\end{tabular}

\section{weakness}

\begin{tabular}{|l||l||}
\hline $\mathrm{a} 01$ & 6 \\
\hline \hline $\mathrm{a} 02$ & 5 \\
\hline \hline $\mathrm{a} 03$ & 6 \\
\hline $\mathrm{a} a 04$ & 6 \\
\hline $\mathrm{a} 05$ & 6 \\
\hline \hline $\mathrm{a} 06$ & 6 \\
\hline
\end{tabular}

\section{qualification}

\begin{tabular}{|c||c|}
\hline a01 & -1 \\
\hline \hline a02 & 1 \\
\hline \hline a03 & 0 \\
\hline \hline a04 & 0 \\
\hline \hline a05 & 0 \\
\hline \hline a06 & 0 \\
\hline
\end{tabular}

Fig 4: Strength, Weakness and Qualification of Alternatives.

\section{Alternatives values}

\begin{tabular}{||l||l||}
\hline a03 & 0 \\
\hline \hline a05 & 0 \\
\hline \hline a06 & 0 \\
\hline \hline a01 & 0.06 \\
\hline \hline a04 & 0.07 \\
\hline \hline a02 & 0.18 \\
\hline
\end{tabular}

Fig 5: Alternatives Values.

From the above scenario, a02 has the highest score. These ELECTRE III approach is tedious and analyzes the networks parameters and its utilization till the core. The ELECTRE III workspace is given by the following Fig: 5 .

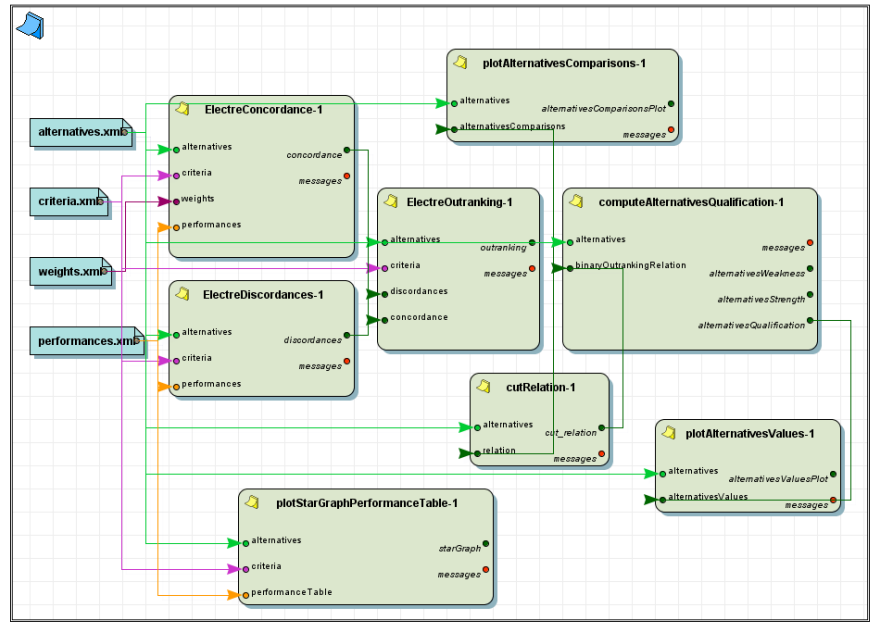

Fig 6: ELECTRE III plot in diviz workspace.

The alternatives, criteria, weights and performance are given as $x m l$ files in diviz[4]. In which it is exactly written in xmcda. The following are the scripts written as xml. For the cut-relation the cut Level value is given as 0.6 and it supplied dynamically. In Table: 5, Input for alternatives are shown. Likewise we supply xml code for Crieria, weights and so on.

Table 5: XML scripts for input values.

\begin{tabular}{|l|}
\hline <xmcda:XMCDA \\
xmlns:xmcda="http://www.decision- \\
deck.org/2009/XMCDA-2.0.0" \\
xmlns:xsi="http://www.w3.org/2001/XMLSchema- \\
instance"> \\
\\
<alternatives> \\
<alternative id="a01" name="GSM" /> \\
<alternative id="a02" name="EDGE" /> \\
<alternative id="a03" name="CDMA" /> \\
<alternative id="a04" name="GSM2" /> \\
<alternative id="a05" name="EDGE2" /> \\
<alternative id="a06" name="CDMA2" /> \\
</alternatives> \\
</xmcda:XMCDA> \\
\end{tabular}

\section{PROMETHEE}

PROMETHEE method is known as Preference Ranking Organization Method for Enrichment of Evaluations. The original PROMETHEE method[3] have been conceived by Jean-Pierre Brans in 1982.With respect to the contemporary ELECTRE methods (ELECTRE III and IV) they brought at the same time more flexible preference modeling capabilities and a greater ease of use. Here the Handoff Decision problem is stated as [5]: Let $A$ be a set of solutions, each $a \in A, f_{j}(a)$ represents the evaluation of a solution $a$, to a given criterion, $f_{j}$. The following Table: 10 is a typical evaluation set. 
Table 6: Evaluation Table

$$
\begin{array}{ccccc} 
& f_{1}(.) & f_{2}(.) & \cdot & f_{j}(.) \\
a_{1} & f_{1}\left(a_{1}\right) & f_{2}\left(a_{1}\right) & \cdot & f_{j}\left(a_{1}\right) \\
a_{2} & f_{1}\left(a_{2}\right) & f_{2}\left(a_{2}\right) & \cdot & f_{j}\left(a_{2}\right) \\
\cdot & \cdot & \cdot & \cdot & \cdot \\
a_{n} & f_{1}\left(a_{n}\right) & f_{2}\left(a_{n}\right) & \cdot & f_{j}\left(a_{n}\right)
\end{array}
$$

\section{1 Promethee Preference}

We define preference function $P_{j}(a, b)$ as the degree of preference of solution $a$ over solution $b$ for a given criteria $f_{j}$. In most cases, we can assume that $P_{j}(a, b)$ is a function of the deviation $d=f(a)-f(b)$. We consider that the function $P_{j}(a, b)$ is normalized, so that:

- $\quad 0 \leq P_{j}(a, b) \leq 1$

- $\quad P(a, b)=0$ if $d \leq 0$, there is no preference or indifference.

- $\quad P(a, b) \approx 0$, if $d>0$, weak preference.

- $\quad P(a, b) \approx 1$, if $d>>0$, Strong preference

- $\quad P(a, b)=1$, if $d>>>0$, Strict preference.

The $p$ and $q$ values are the indifference and preference thresholds respectively. A multi-criteria preference index $\pi$ $(a, b)$ of $a$ over $b$ can then be defined, that takes all the criteria into account with the expression following.

$\pi(a, b)=\sum_{j=1}^{k} w_{j} p_{j}(a, b)$

where $w_{j}>0$ are weights associated with each criterion. These weights are positive real numbers that do not depend on the scales of the criteria.

- The positive outranking flow is given by

$$
\Phi^{+}(a)=\frac{1}{n-1} \sum_{b \in A, b \neq a} \pi(a, b)
$$

- The Negative outranking flow is given by

$$
\Phi^{-}(a)=\frac{1}{n-1} \sum_{b \in A, b \neq a} \pi(b, a)
$$

\subsection{Promethee Ranking:}

Two rankings of the alternatives can be deduced naturally from the positive and the negative outranking flows. The calculation of ranking is done by implementing the alternatives and criterions values in diviz workspace. The following table is the Performance Table: 7 obtained by PROMETHEE method. In which it shows that criteria Data rate and Speed has influenced over all other criteria. And as a whole EDGE performance overwhelms other networks.

Table7: Performance Table

\section{Performance table}

\begin{tabular}{||l||l||l||l||l||l||l||}
\hline & c06 & c01 & c03 & c02 & c05 & c04 \\
\hline \hline a06 & 0 & -0.2 & -0.4 & 0 & 0 & 0 \\
\hline \hline a04 & 0 & -0.2 & 0.48 & 0 & 0 & 0 \\
\hline \hline a05 & 0 & 0 & -0.08 & 0 & 0 & 0 \\
\hline \hline a02 & 0 & 0.8 & 0 & 0 & 0 & 0 \\
\hline \hline a03 & 0 & -0.2 & -0.37 & 0 & 0 & 0 \\
\hline \hline a01 & 0 & -0.2 & 0.37 & 0 & 0 & 0 \\
\hline
\end{tabular}

\subsection{Geometrical Analysis for Interactive \\ Aid (GAIA)}

The objective of GAIA Plane is to describe the relationship between actions. Whether the criteria are conflicting with each other or they have similar preferences. And it is also used to show the impact of the weights of criteria on the PROMETHEE rankings. In the following Fig:6, Delta is a quality measure of GAIA representation. If the Delta value is low then the GAIA quality is not consistent and requires careful analysis. The alternative a02 which is EDGE, has good datarate when compared to other alternatives. It is totally opposite to all other alternatives. GSM and GSM2( a01,a04 ) behaviors are almost same and both has same velocity level. CDMA and CDMA2 has similarity.

\section{Gaia plane}

$\{a 06, a 04, a 05, a 02, a 03, a 01\}$

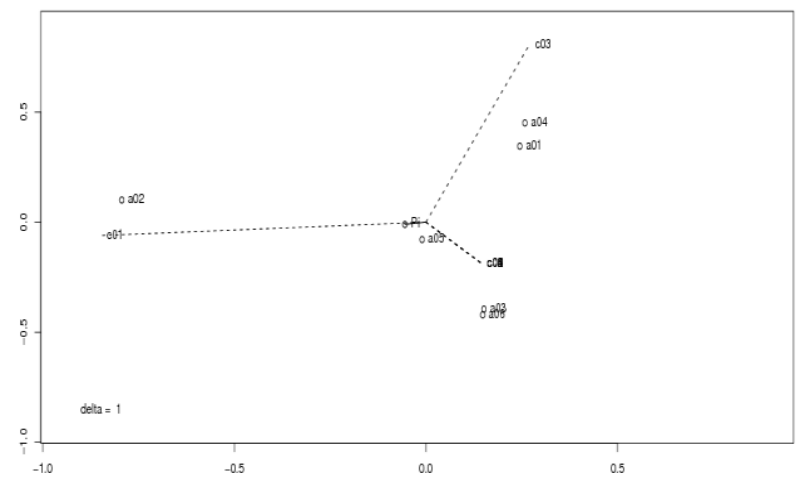

Fig 7: GAIA Plane representation of Networks and parameters.

As like ELECTRE III method, for PROMETHEE method also we implemented on diviz[4] workspace which is given by the following Fig: 8 . 


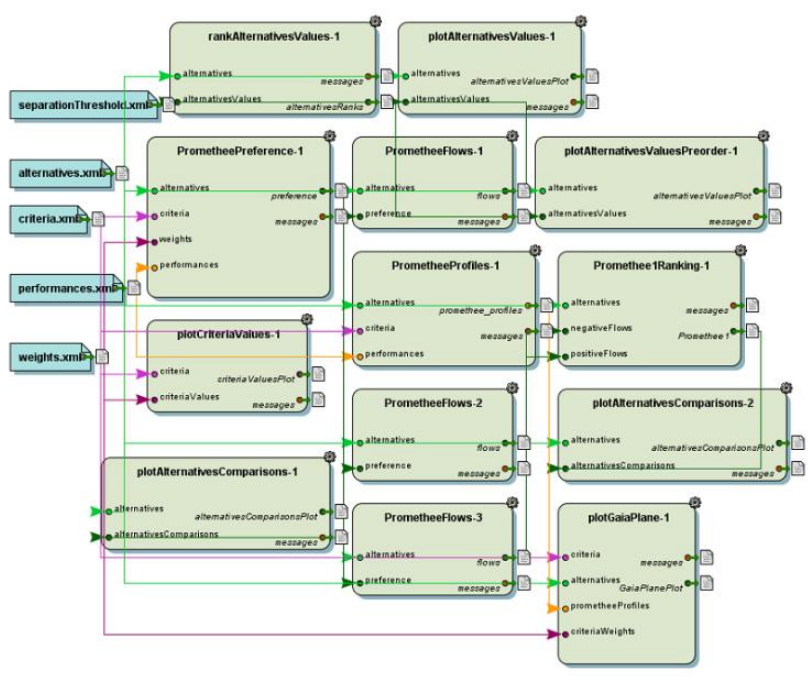

Fig 8: PROMETHEE implementation in Diviz workspace.

From the above Fig: 8 , It is clear that there are 4 significant input files named as alternatives, criteria, performances and weights which are supplied to the models Promethee preference, plot criteria, rank Alternatives etc,. The input file separation Threshold is an optional one. And here the cut Level is not required. By executing these workspace we will achieve the handoff decision of which alternative to select.

\section{SIMULATION}

From the Table: 6 , the concordance values of networks over other networks are obvious.

\section{Alternatives values plot}

$\{a 01, a 02, a 03, a 04, a 05, a 06\}$

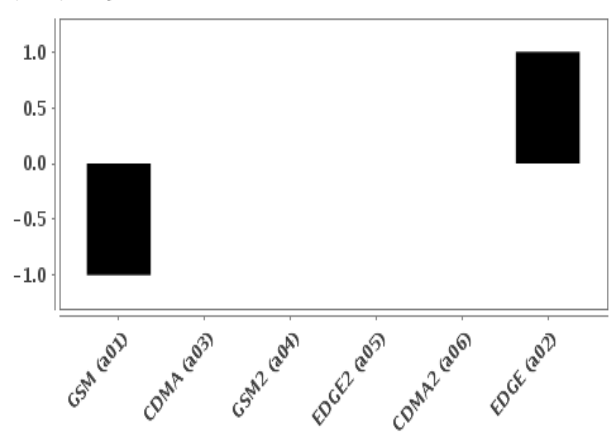

Fig 9: Credibility Index of Networks by ELECTRE III Method

Alternatives values plot

$\{\mathrm{a} 01, \mathrm{a} 02, \mathrm{a} 03, \mathrm{a} 04, \mathrm{a} 05, \mathrm{a} 06\}$

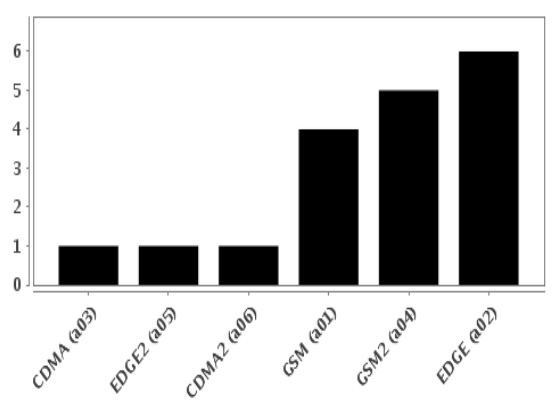

Fig 10: Index of Networks by PROMETHEE Method

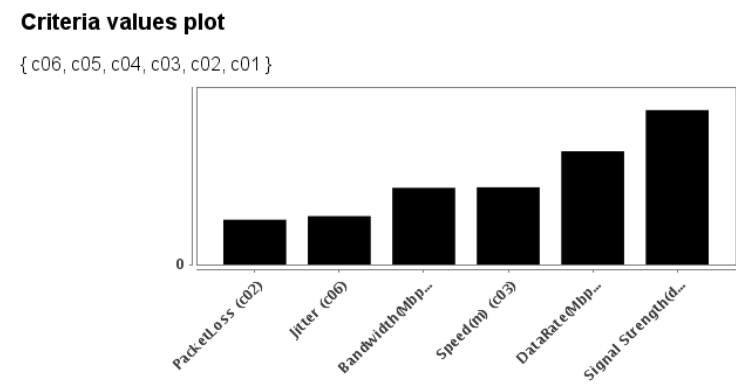

Fig 11: Index of Criteria by PROMETHEE method

The credibility index has been estimated and it is clear that Network a02 has the highest credibility over other networks. Next a04 scores high according to PROMETHEE method. In this section, the evaluation parameters were used to analyze the performance of the proposed ELECTRE III method as well as the output and analysis of the simulation. In our work we consider that mobile nodes are moving uniformly in an area covered by $\mathrm{N}$ networks managed by Different Base Stations. Mobility area consists of three types of technologies; GSM, EDGE and CDMA. We assume that mobile node is always covered by at two three networks. Here we consider 3 specific networks. ELECTRE III results shows that EDGE network gives better performance when the cut-off level is 0.6. ELECTRE III Method analyzes all perspectives of the given networks and their criterions. From the Fig 5, the implementation of PROMETHEE method calculates the Preference Relation of given networks by using each criteria. From that EDGE and GSM2 outperforms other networks.

\section{OUTPUT AND ANALYSIS}

In this paper we proposed a two MADM technique for the handoff decision making of heterogeneous wireless networks. Our work incorporated the parameters such as Throughput, Coverage Area, Dwell Time and Latency incurred on the network for the seamless mobility. The Evaluation is based on ELECTRE III and PROMETHEE methods. ELECTRE III method deals with 3 aspects. Firstly the Concordance index is calculated and Discordance index is measured. Finally Credibility index is calculated. Outranking Relationships among the networks are explained with Fig 2. From that, Weakness and Strength of each network is calculated. Performance of Networks with threshold ( cut-off ) value is calculated. In ELECTRE III method EDGE acquired high rank. In PROMETHEE method, we have calculated the Preference Level. PROMETHEE method mainly incorporates the positive and negative flow of each criterion and based on that the performance is estimated.

Table8: Simulation Parameters

\begin{tabular}{|l|l|}
\hline Topology Shape & 500 Meter * 500 Meter \\
\hline Radio range of each node & $170-200$ Meters \\
\hline Transmission Capacity & $1.5 \mathrm{Mbps}$ \\
\hline Base Station & Multi Hop / Hierarchical \\
\hline Node Count & $10-20$ \\
\hline $\begin{array}{l}\text { Average transmission of } \\
\text { Packets }\end{array}$ & 2 packets \\
\hline Maximum speed of a node & 5 meters / second \\
\hline Node moments & Random \\
\hline Simulation Time & 60 seconds \\
\hline
\end{tabular}


From the above Table: 8 the simulation parameters for execution of handoff decision can be obtained. Tracegraph 202 tool exploited for analyzing the packet delivery, throughput and delay. From the Fig 5, it shows the cumulative sum of all the packets received at time.

\section{CONCLUSION}

An implementation of a seamless vertical handoff procedure and the effective Fuzzy ELECTRE III and SAW Methods for the handoff transition region between the GSM, CDMA, WIFI and WIMAX cellular network is presented. The Fuzzy ELECTRE and SAW Methods, as shown by the simulation results, does not result in excessive swaps between the GSM, CDMA and WIMAX networks and hence would provide quite a useful tool for the device in real time functioning. On the other hand, the ELECTRE method has some drawbacks. The major weakness is that if the parameters are not chosen rightly the method would result in an inefficient usage of resources performance. In contrast, SAW method implementation is simple. Risk Factor examines the criterion values. Among the networks, GSM and CDMA gives better performance since it uses soft handoff in which there is no connection loss. By using fuzzy ELECTRE III method, we can choose the relevant networks for handoff. By Calculating Concordance, Discordance and Credibility matrices we can select the best network for handoff, thus reducing the unwanted handoff and handoff failures. Several issues require further research and development. In future, we will graft on reducing the packet drops and will work on reducing the noise and traffic.

\section{ACKNOWLEDGEMENT}

The First Author extends her gratitude to UGC as this research work was supported by Major Research Project, under grant reference number, 41-611/2012(SR), UGC XI Plan.

\section{REFERENCES}

[1] Ali Çalhan, Celal Çeken. (2012) "An Optimum Vertical Handoff Decision Algorithm Based on Adaptive Fuzzy Logic and Genetic Algorithm", Wireless Pers Commun Vol.64, pp.647-664.
[2] B. Roy. (1991) The Outranking Approach and the Foundation of ELECTRE Methods, Theory and Decision, Vol.31, pp 49-73.

[3] Cathy Macharis et.al., (2004) "PROMETHEE and AHP: The design of operational synergies in multicriteria analysis. Strengthening PROMETHEE with ideas of AHP", European Journal of Operational Research, pp.307-317.

[4] Jordi Canals Ros. (2011) "Introduction to decision deck diviz - Examples and User Guide". http://www.decisiondeck.org/diviz/_static/ReportDecisionDeck-DEIMURV.pdf

[5] Philippe Vincke. (1989) "Multicriteria decision aid", John Wiley and sons.

[6] Preethi.G.A, Chandrasekar.C. (2013) "A network selection algorithm based on AHP-OWA methods", 6th Joint IFIP Wireless and Mobile Networking Conference (WMNC), pp.1-4.

[7] Naeem, B. and A. Nyamapfene. (2011) "Seamless Vertical Handover in WiFi and WiMAX Networks Using RSS and Motion Detection: An Investigation". Pacific Journal of Science and Technology, Volume:12, No.1, pp.298-304.

[8] Shengmei Liu, Zhongjiu Zheng, and Su Pan. (2013) “A Novel PROMSIS Vertical Handoff Decision Algorithm for Heterogeneous Wireless Networks", International Journal of Distributed Sensor Networks. vol. 2013, Article ID 846791, 6 pages. doi:10.1155/2013/846791

[9] Yicui, Klara N and Dongyan X. (2004) "Seamless UserLevel Handoff in Ubiquitous Multimedia Service Delivery", Multimedia Tools and Applications, Vol.22, pp.137-170. 